Pacific Journal of Mathematic 


\title{
A NONIMBEDDING THEOREM OF ASSOCIATIVE ALGEBRAS
}

\author{
ERNEST L. STITZINGER
}

\begin{abstract}
Let $A$ and $B$ be associative algebras and define the Frattini subalgebra of $A, \phi(A)$, to be the intersection of all maximal subalgebras of $A$ if maximal subalgebras of $A$ exist and as $A$ otherwise. Conditions on $B$ will be found such that $B$ cannot be an ideal of $A$ contained in $\phi(A)$.
\end{abstract}

Hobby in [2] has shown that a nonabelian group $G$ cannot be the Frattini subgroup of any $p$-group if the center of $G$ is cyclic. Chao in [1] has shown that a nonabelian Lie algebra $L$ can not be the Frattini subalgebra of any nilpotent Lie algebra if the center of $L$ is one dimensional. In this note, we find a similiar result in the theory of associative algebras. However, in this case, it is not necessary to place any restrictions on the containing algebra.

Let $A$ be an associative algebra over a field $F$ and let $B$ be an ideal of $A$. If $x \in A$, then $x$ induces an endomorphism of the additive group of $B$ by $L_{x}(b)=x b$ for all $b \in B$. Let $E(B, A)$ be the collection of all endomorphisms of this type. Then $E(B, A)$ is a subspace of the vector space of all linear transformations from $B$ into $B$ and is an associative algebra under the compositions $L_{x}+L_{y}=L_{x+y}, \alpha L_{x}=$ $L_{\alpha x}$ and $L_{x} L_{y}=L_{x y}$ for all $x, y \in A$ and all $\alpha \in F$. Clearly $E(B, B)$ is an ideal of $E(B, A)$. If $C$ is an ideal of $A$ contained in $B$, then let $E(B, A, C)=\{E \in E(B, A) ; E(c)=0$ for all $c \in C\}$. Then $E(B, A, C)$ is an ideal of $E(B, A)$ and $E(B, A) / E(B, A, C)$ is isomorphic to $E(C, A)$. Note that the mapping from $A$ onto $E(B, A)$ which assigns to each $a \in A$ the element $L_{a}$ is an algebra homomorphism. We define the right annihilating series of $B$ inductively. Let $r_{1}(B)=\{c \in B ; b c=0$ for all $b \in B\}$ and let $r_{j}(B)$ be the ideal of $B$ such that $r_{j}(B) / r_{j-1}(B)$ $r_{1}\left(B / r_{j-1}(B)\right)$ for $j>1$. Since $B$ is an ideal in $A, r_{i}(B)$ is an ideal in $A$ for all $i$.

The following lemma is immediate.

Lemma. If $A$ and $A^{\prime}$ are associative algebras and $\pi$ is a homomorphism from $A$ onto $A^{\prime}$, then $\pi(\phi(A)) \subseteq \dot{\phi}(\pi(A))$. Furthermore, if the kernel of $\pi$ is contained in $\phi(A)$, then $\pi(\phi(A))=\phi(\pi(A))$.

THEOREM. Let $B$ be an associative algebra such that $\operatorname{dim} r_{1}(B)=$ 1 and $\operatorname{dim} r_{2}(B)=k$ where $1<k<\infty$. Then $B$ cannot be an ideal contained in the Frattini subalgebra of any associative algebra. 
Proof. Suppose that to the contrary $B$ is an ideal contained in the Frattini subalgebra of the associative algebra $A$. Then

$$
E(B, B) \subseteq \phi(E(B, A)) .
$$

For if $T$ is the mapping from $A$ onto $E(B, A)$ defined by $T(a)=L_{a}$ for all $a \in A$, then, by the lemma,

$$
E(B, B)=T(B) \subseteq T(\phi(A)) \subseteq \phi(T(A))=\phi(E(B, A)) .
$$

Let $z_{1}, \cdots, z_{k}$ be a basis for $r_{2}(B)$ such that $z_{k}$ is a basis $r_{1}(B)$. For notational convenience, let $r_{i}=r_{i}(B)$ for all $i$. Let $\pi$ be the natural homomorphism from $E(B, A)$ onto $E\left(r_{2}, A\right)$. Since

$$
\begin{aligned}
& E(B, B)+E\left(B, A, r_{2}\right) / E\left(B, A, r_{2}\right) \simeq E(B, B) / E\left(B, A, r_{2}\right) \cap E(B, B) \\
& \quad=E(B, B) / E\left(B, B, r_{2}\right) \simeq E\left(r_{2}, B\right)
\end{aligned}
$$

it follows that

$$
E\left(r_{2}, B\right) \simeq \pi(E(B, B)) \subseteq \pi(\phi(E(B, A))) \subseteq \phi\left(E\left(r_{2}, A\right)\right) .
$$

We now show that $E\left(r_{2}, B\right) \not \Phi \phi\left(E\left(r_{2}, A\right)\right)$ by showing that $E\left(r_{2}, B\right)$ is complemented in $E\left(r_{2}, A\right)$. For $i=1, \cdots, k-1$, define linear transformations $e_{i}$ from $r_{2}$ onto $r_{1}$ by

$$
e_{i}\left(z_{j}\right)= \begin{cases}\delta_{i j} z_{k} & \text { for } j=1, \cdots, k-1 \\ 0 & \text { for } j=k\end{cases}
$$

where $\delta_{i j}$ is the Kronecker delta. Let $S=\left(\left(e_{1}, \cdots, e_{k-1}\right)\right)$. We claim that $S=E\left(r_{2}, B\right)$. Since $r_{1}=\left(\left(z_{k}\right)\right)$ and $B \cdot r_{2} \subseteq r_{1}, E\left(r_{2}, B\right) \subseteq S$. To show that $S=E\left(r_{2}, B\right)$, we shall show that $\operatorname{dim} E\left(r_{2}, B\right)=k-1=$ $\operatorname{dim} S$. For each $x \in B, L_{x}$ induces a linear transformation from $r_{2}$ into $r_{1} \simeq F$, where $F$ is the ground field. Therefore, we may consider each $L_{x}, x \in B$ as a linear functional on $r_{2}$. That is, $E\left(r_{2}, B\right) \subseteq\left(r_{2}\right)^{*}$ where $\left(r_{2}\right)^{*}$ is the dual space of $r_{2}$. Consequently, $\operatorname{dim} E\left(r_{2}, B\right)=\operatorname{dim}$ $r_{2}-\operatorname{dim} r_{2}^{B}$ where $r_{2}^{B}=\left\{z \in r_{2} ; L_{x}(z)=0\right.$ for all $\left.x \in B\right\}$. Clearly $r_{2}^{B}=r_{1}$. Then, since $\operatorname{dim} r_{2}=k$ and $\operatorname{dim} r_{1}=1, \operatorname{dim} E\left(r_{2}, B\right)=k-1$ and $S=$ $E\left(r_{2}, B\right)$.

We now show that $S$ is complemented in $E\left(r_{2}, A\right)$. Let $M=\left\{E \in E\left(r_{2}, A\right) ; E\left(z_{i}\right)=\sum_{j=1}^{k-1} \lambda_{i j} z_{j}, \lambda_{i j} \in F, i=1, \cdots, k-1\right.$

and $\left.E\left(z_{k}\right)=\lambda_{k} z_{k}, \lambda_{k} \in F\right\} . \quad M$ is clearly a subalgebra of $E\left(r_{2}, A\right)$ and $M \cap S=0$. We claim that $M+S=E\left(r_{2}, A\right)$. Let $E \in E\left(r_{2}, A\right)$. Then $E\left(z_{i}\right)=\sum_{j=1}^{k-1} \lambda_{i j} z_{j}+\lambda_{i k} z_{k}$ for $i=1, \cdots, k-1$ and $E\left(z_{k}\right)=\lambda_{k} z_{k}$. However $E=E-\sum_{i=1}^{k-1} \lambda_{i k} e_{i}+\sum_{i=1}^{k-1} \lambda_{i k} e_{i}$ where $E-\sum_{i=1}^{k-1} \lambda_{i k} e_{i} \in M$ and $\sum_{i=1}^{k-1} \lambda_{i k} e_{i} \in S$. Therefore $M+S=E\left(r_{2}, A\right)$. We claim that $M \neq 0$. If $M=0$, then $E\left(r_{2}, A\right)=E\left(r_{2}, B\right)$ which contradicts 


$$
E\left(r_{2}, B\right) \subseteq \phi\left(E\left(r_{2}, A\right)\right) \subset E\left(r_{2} A\right) .
$$

Consequently, $S$ is complemented in $E\left(r_{2}, A\right)$, contradicting $S \subseteq$ $\phi\left(E\left(r_{2}, A\right)\right)$. This contradiction establishes the result.

Corollary. Let $B$ be a finite dimensional nontrivial nilpotent associative algebra with $\operatorname{dim} r_{1}(B)=1$. Then $B$ cannot be an ideal contained in the Frattini subalgebra of any associative algebra.

\section{REFERENCES}

1. C. Y. CHAO, A nonimbedding theorem of nilpotent Lie algebras, Pacific J. Math. 22 (1967), 231-234.

2. C. Hobby, The Frattini subgroup of a p-group, Pacific J. Math. 10 (1960), 209212.

Received January 23, 1969. This paper is part of the author's doctoral dissertation at the University of Pittsburgh.

UNIVERSITY OF PITTSBURGH 



\title{
PACIFIC JOURNAL OF MATHEMATICS
}

\author{
EDITORS
}

H. ROYDEN

Stanford University

Stanford, California

R. R. PhelPS

University of Washington

Seattle, Washington 98105
J. DUGUNDJI

Department of Mathematics

University of Southern California

Los Angeles, California 90007

RICHARD ARENS

University of California

Los Angeles, California 90024

\section{ASSOCIATE EDITORS}
E. F. BECKENBACH
B. H. NeumanN
F. WOLF
K. YoSHIDA

\section{SUPPORTING INSTITUTIONS}

\author{
UNIVERSITY OF BRITISH COLUMBIA \\ CALIFORNIA INSTITUTE OF TECHNOLOGY \\ UNIVERSITY OF CALIFORNIA \\ MONTANA STATE UNIVERSITY \\ UNIVERSITY OF NEVADA \\ NEW MEXICO STATE UNIVERSITY \\ OREGON STATE UNIVERSITY \\ UNIVERSITY OF OREGON \\ OSAKA UNIVERSITY \\ UNIVERSITY OF SOUTHERN CALIFORNIA
}

\author{
STANFORD UNIVERSITY \\ UNIVERSITY OF TOKYO \\ UNIVERSITY OF UTAH \\ WASHINGTON STATE UNIVERSITY \\ UNIVERSITY OF WASHINGTON \\ $\stackrel{*}{*} \stackrel{*}{*}{ }^{*}{ }^{*}$ \\ CHEVRON RESEARCH CORPORATION \\ TRW SYSTEMS \\ NAVAL WEAPONS CENTER
}

The Supporting Institutions listed above contribute to the cost of publication of this Journal, but they are not owners or publishers and have no responsibility for its content or policies.

Mathematical papers intended for publication in the Pacific Journal of Mathematics should be in typed form or offset-reproduced, double spaced with large margins. Underline Greek letters in red, German in green, and script in blue. The first paragraph or two must be capable of being used separately as a synopsis of the entire paper. It should not contain references to the bibliography. Manuscripts, in duplicate if possible, may be sent to any one of the four editors. Please classify according to the scheme of Math. Rev. 36, 1539-1546. All other communications to the editors should be addressed to the managing editor, Richard Arens, University of California, Los Angeles, California, 90024.

50 reprints are provided free for each article; additional copies may be obtained at cost in multiples of 50 .

The Pacific Journal of Mathematics is published monthly. Effective with Volume 16 the price per volume (3 numbers) is $\$ 8.00$; single issues, $\$ 3.00$. Special price for current issues to individual faculty members of supporting institutions and to individual members of the American Mathematical Society: $\$ 4.00$ per volume; single issues $\$ 1.50$. Back numbers are available.

Subscriptions, orders for back numbers, and changes of address should be sent to Pacific Journal of Mathematics, 103 Highland Boulevard, Berkeley, California, 94708.

PUBLISHED BY PACIFIC JOURNAL OF MATHEMATICS, A NON-PROFIT CORPORATION

Printed at Kokusai Bunken Insatsusha (International Academic Printing Co., Ltd.), 7-17, Fujimi 2-chome, Chiyoda-ku, Tokyo, Japan. 


\section{Pacific Journal of Mathematics \\ Vol. 30, No. $2 \quad$ October, 1969}

Gregory Frank Bachelis, Homomorphisms of annihilator Banach algebras.

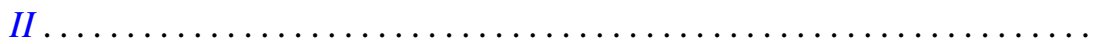

Leon Bernstein and Helmut Hasse, An explicit formula for the units of an algebraic number field of degree $n \geq 2 \ldots \ldots \ldots \ldots \ldots \ldots \ldots . \ldots 29$

David W. Boyd, Best constants in a class of integral inequalities ........ 367

Paul F. Conrad and John Dauns, An embedding theorem for lattice-ordered

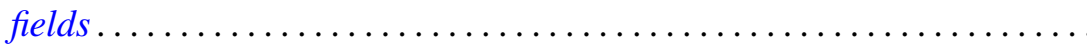

H. P. Dikshit, Summability of Fourier series by triangular matrix

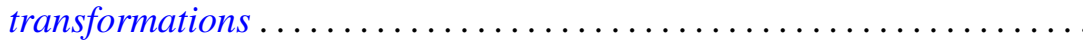

Dragomir Z. Djokovic, Linear transformations of tensor products preserving a fixed rank............................. 411

John J. F. Fournier, Extensions of a Fourier multiplier theorem of Paley . . . 415 Robert Paul Kopp, A subcollection of algebras in a collection of Banach

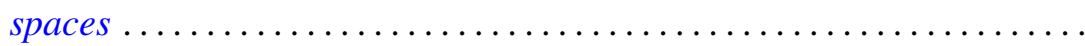

Lawrence Louis Larmore, Twisted cohomology and enumeration of vector bundles ...................................... 437

William Grenfell Leavitt and Yu-Lee Lee, A radical coinciding with the lower radical in associative and alternative rings .................

Samuel Merrill and Nand Lal, Characterization of certain invariant subspaces of $H^{p}$ and $L^{p}$ spaces derived from logmodular

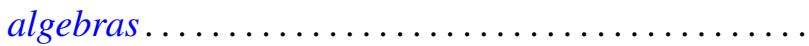

Sam Bernard Nadler, Jr., Multi-valued contraction mappings ....

T. V. Panchapagesan, Semi-groups of scalar type operators in Banach spaces ....................................

J. W. Spellmann, Concerning the infinite differentiability of semigroup motions

H. M. (Hari Mohan) Srivastava, A note on certain dual series equations involving Laguerre polynomials.

Ernest Lester Stitzinger, A nonimbedding theorem of associative algebras................................

J. Jerry Uhl, Jr., Martingales of vector valued set functions ...

John Mays Worrell Jr., On continuous mappings of metacompact $\check{C} e c h$

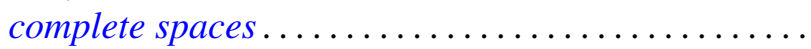

